\title{
Poética, erótica y políticas del nombre propio: de la magia a la autobiografía ${ }^{1}$
}

Poetic, Erotic and Politics of the Proper Name: from Magic to Autobiography

\section{Lorena Amaro}

Instituto de Estética. Pontificia Universidad Católica de Chile. Santiago

lamaro@puc.cl

Resumen - Desde diversas disciplinas, Occidente se ha interrogado sobre las implicancias mágicas, poéticas y políticas del nombre propio. El siguiente artículo aborda desde las relaciones de analogía que en torno a él tejen la cábala y la magia, hasta conceptualizaciones modernas y contemporáneas sobre su lugar en la literatura, particularmente en lo referente a sus relaciones con el sujeto y el texto, como también a sus proyecciones en el nombre de autor y su firma, aparentemente centrales en la construcción del discurso autobiográfico.

Palabras clave: Nombre propio, Autobiografía, Auto, Firma.

Abstract • From a wide range of disciplines, the Western world has asked itself the question regarding the magic, poetic and political implications of the proper name. The following article raises issues that start with the analogies that both cabbala and magic weave around the proper name, to the modern and contemporary conceptualizations about the place of the proper name in literature. This latter is achieved particularly in reference to its connections with the subject and text, and also in reference to its projections on the name of the author and his signature, both apparently central in the construction of the autobiographical discourse.

Keywords: Proper name, Autobiography, Author, Signature. 
"¿Qué hay en un nombre? Eso es lo que nos preguntamos en la niñez cuando escribimos el nombre que nos han dicho es el nuestro".

(James Joyce)

"Escribo para borrar mi nombre..."

Entre las primeras palabras que balbucea un niño se encuentra su propio nombre. Antes de que entendamos lo que es "yo", o "tú", sabemos que hay una palabra que nos designa. ¿Cuántos de nosotros no hemos llenado alguna vez una página con el trazo compulsivo y monótono, de nuestro propio nombre? Jorge Luis Borges, cuyos textos merodean de forma obsesiva este tema, constituyendo una verdadera "poética", escribe un interesante párrafo acerca de la relación entre los nombres y la magia

los aborígenes de Australia reciben nombres secretos que no deben oír los individuos de la tribu vecina. Entre los antiguos egipcios, prevaleció una costumbre análoga; cada persona recibía dos nombres: el nombre pequeño que era de todos conocido, y el nombre verdadero o gran nombre, que se tenía oculto. Según la literatura funeraria, son muchos los peligros que corre el alma después de la muerte del cuerpo; olvidar su nombre (perder su identidad personal) es acaso el mayor. También importa conocer los verdaderos nombres de los dioses, de los demonios y de las puertas del otro mundo [...] De Quincey nos recuerda que era secreto el verdadero nombre de Roma; en los últimos días de la República, Quinto Valerio Sorano cometió el sacrilegio de revelarlo, y murió ejecutado... (Borges, 1999b: 128).

Borges toca el asunto en diversos textos y suele destacar el hecho de que, incluso los más mínimos cambios o lesiones hechos al nombre, tengan para el pensamiento analógico una importancia radical. Relata, por ejemplo, cómo al ángel Satanail le cercenaron la partícula il de su nombre, que aseguraba su esplendor, relegándolo al fuego, o cómo Abram fue estéril hasta que incorporaron a su nombre la partícula he, para que fuese capaz de engendrar (Borges, 1999a: 421). Los dos ejemplos revelan la atávica necesidad de acoplar dos imágenes, la de una persona y su nombre. El pensamiento mágico establece este tipo de relación: es así como cualquier daño o cambio hecho a un nombre, afecta a quien lo detenta. Los ejemplos son muchos, y se pueden perseguir en el campo de la antropología como también en el estudio de la cábala y las corrientes gnósticas del lenguaje. Para el Talmud, por ejemplo, "omitir o añadir una sola letra puede llevar a la destrucción de mundo entero" (Steiner, 1980: 81). Muchas generaciones leyeron los textos sagrados desde la Cábala, intentando dar con el nombre o los nombres secretos de Dios.

Al fin y al cabo, la metonimia y la magia van de la mano: el nombre es la parte del yo que parece expresar una presencia en el mundo, aunque existan otros que se llamen como nosotros. Y esta atávica conexión se proyecta de algún modo en las costumbres actuales, por ejemplo, dar a los hijos dos o más nombres o castigar los delitos de calumnia e injuria, daños realizados contra el nombre de una persona.

La literatura prolonga la fascinación por la onomástica, por sus ecos, sus resonancias. Según Roland Barthes en el ensayo "Proust y los nombres", esto es así hasta tal punto que los nombres propios en la gran novela de Marcel Proust, En busca del tiempo perdido, funcionan como unidades poéticas del discurso, capaces de constituir la esencia del objeto novelesco. A su modo de ver, el nombre propio es la forma lingüística de la reminiscencia, elemento primordial de la empresa de recuerdo proustiana: "Por lo tanto, el acontecimiento (poético) que ha "lanzado" la obra, es el descubrimiento de los Nombres" (Barthes, 1973: 176). El propio Marcel Proust deja traslucir esta búsqueda, tanto en Contra Sainte-Beuve, como en Por el camino de Swann. Proust sabía que no podía existir una identidad entre la "poesía desconocida" de los nombres que le fascinaban (como Combray o Guermantes), "una urna de cosas desconocidas" y las cosas mismas: una decepción latía en el fondo de todo ello. Aun así, le parecía que era válido soñar, como soñamos y evocamos todos a partir de ciertos nombres; había que remontar ese realismo que enajena a las palabras de las cosas, para alcanzar otro, uno que tuviese por objeto "una realidad [...] mucho más vivaz que la otra”. Una realidad que:

...desertando de los países que hemos visitado, alcanza todavía a todos los demás, y recubre de nuevo aquellos a los que hemos conocido una vez que estan algo olvidados y que han vuelto a ser para nosotros nombres, puesto que ella nos acosa incluso en sueños, y da a los países, a las iglesias de nuestra infancia, a los castillos de nuestros sueños, la apariencia de tener la misma naturaleza que los nombres, la apariencia hecha de imaginación y de deseo que no volvemos a encontrar una vez despiertos, o en el momento en que, dándonos cuent molesta y nos decepciona... (Proust, 1970).

Esta poética del nombre es común a la literatura; contagia al propio teórico Roland Barthes, aquél que "sufre si es nombrado" (1978: 47), pero que también goza con el recuerdo de los nombres de la infancia, los nombres propios de la vieja burguesía bayonesa, medio en el cual fue criado por su madre:

¿Cómo puede tenerse una relación amorosa con unos nombres propios? Ni la menor sospecha de metonimia: esas señoras no eran nada atractivas, ni siquiera graciosas. Y, sin embargo, me
es imposible leer una novela, una memoria, sin esa golosidad particular (leyendo a Mme. de Genlis, acecho con interés los nombres de la vieja nobleza). No es sólo una lingüística de los nombres propios lo que hace falta; es también una erótica: el nombre, como la voz, como el olor, sería el término de una languidez: deseo y muerte: "el último suspiro que queda de las cosas", dice un autor del siglo pasado... (Barthes, 1978: 56-7).

Parece injusto extenderse en el comentario de este fragmento que, como tal, busca el goce inmediato. No obstante, la erótica a la cual se refiere Barthes es una forma de goce de lo artístico o literario: es la forma que, según él, debe adquirir un discurso estético. Esta erótica del nombre es también un atavismo inexplicable, pero hermoso:

La literatura es exploración del nombre: Proust ha sacado todo un mundo de esos pocos sonidos: Guermantes. En el fondo, el escritor tiene siempre la creencia de que los signos so arbitrarios y que el nombre es una propiedad natural de la cosa... (Barthes, 1981: 54).

Proust y Barthes invitan a pensar en la función que el nombre tiene en el imaginario; en cómo el nombre propio moviliza el recuerdo y cómo se convierte en el motor de una poética. Pero hay otros modos de aproximarse al enigma de los nombres. Ellos no sólo inspiran la poesía y las búsquedas liberadoras del lenguaje; el uso de los nombres tam- 
bién se vincula con el ejercicio del poder, y así como es posible fundar una erótica de los nombres, también se puede hablar, siguiendo sobre todo a Jacques Derrida, de políticas del nombre propio, como mostraré más adelante.

\section{NOMBRE PROPIO Y PENSAMIENTO OCCIDENTAL}

El temor expresado en la biografía de Barthes, el temor a ser nombrado, quizás se explica porque nombrar es una forma de ejercer el poder. Dios permite a Adán dar a las cosas el Las injurias y calumnias a las que aludí antes, como las prácticas mágicas que en torno al nombre tejían las sociedades tribales, constituyen formas de ejercer poder -y violencia- sobre otra persona. Incluso no hay que olvidar que, más allá del plano mágico, el nombre propio es también una herencia que, al menos en el ámbito occidental, se obtiene preferentemente del padre y prescribe ciertos derechos de propiedad. Como otros elementos del patrimonio, el patronímico constituye desde antiguo un signo de poder. En el mundo clásico, por ejemplo, "para gozar de una buena vida, se dependía del bienestar y caudal del oikos o patrimonium de la familia. Más importante era lo que se tenía que lo que se podía ser, y sólo los nobles tenían un nombre propio" (Weintraub, 30). El resto eran los "proletarios", una vasta masa de "sujetos innominados" (ibíd.) cuya única posesión era su prole. La heredad del nombre, por tanto, conlleva una historia de exclusiones, censuras y desgarros.

Esto es así al menos en la historia de Occidente, donde se produce una particular comprensión de la relación del lenguaje con el mundo. En su presentación de De la gramatología, Phillipe Sollers plantea que la metafísica occidental se produce como dominio de una forma lingüística: "Encarnando la mortalidad de la letra, se fortalece un elemento fundamental: el nombre" (Sollers, 1971). En China, argumenta Sollers, se produce el fenómeno de la escritura no-fonética, la cual rompe con el sistema del nombre como denominación: en la escritura ideogramática, el nombre constituye el producto de unas relaciones entre sus componentes. Existe, entonces, una forma distinta de apropiación del nombre, producto de un sistema de pensamiento y escritura diferentes.

La reflexión sobre las relaciones entre los nombres y las cosas se gestiona desde la Grecia antigua, donde se genera la teoría de la armonía imitativa de los nombres, como testimonia el Cratilo de Platón, diálogo en que se plantea el problema de si los nombres (en general, aunque también los propios) se corresponden con la esencia de las cosas o son tan sólo producto de una convención. La pregunta está allí: ¿qué es un nombre en realidad? A Platón le importaba precisar si el nombre sirve o no como instrumento de conocimiento. Por lo que se puede concluir del Cratilo, se mostró poco favorable a esta hipótesis²

La discusión sobre el nombre seguiría su curso en los textos aristotélicos, como asimismo en la Edad Media, con la conocida controversia que sobre los universales sostuvieron

En este diálogo, Sócrates pone en duda tanto la teoría de Hermógenes (el lenguaje como convención social) como la de Cratilo (el lenguaje en correspondencia con la esencia de las cosas). Finalmente, parece que la única conclusión posible es la que sigue: "El medio según el cual hay que llegar al conocimiento y dominio de las cosas quizás sea una capacidad que no esté a mi alcance ni al tuyo. Contentémonos con haber llegado a un acuerdo en el que el conocimiento no debe partir de los nombres, sino que con mucha más razón hay que llegar a conocer y descubrir las cosas a partir de sí mismas y no de los nombres” (Platón, 62). De este modo, el filósofo refuerza su teoría de las ideas como medio de conocimiento. nominalistas y realistas; la cuestión del nombre y su relación con la esencia de las cosas aparece también en la tradición cabalística judía, llegando a ejercer influencia en los primeros esbozos de una moderna filosofía del lenguaje: a diferencia de Platón, los gnósticos del lenguaje sí pensaban que éste podía ser un medio para llegar a la verdad.

\section{NACIMIENTO Y MUERTE DEL AUTOR}

Proust temía la decepción de los nombres. Efectivamente, en el tiempo de las palabras y las cosas ha caído hace mucho tiempo el velo de la ilusión referencial. Puede ser que los nombres propios -como los nombres de Dios- carezcan ya de toda magia efectiva. Sin embargo, hay nombres que parecen afirmarse en su sitio, y que parecen designar en sí mismos un universo de significados. Estos nombres son los que están refrendados por la fama: pensamos, particularmente, en el nombre de autor.

El nombre de autor, como argumenta Michel Foucault en el artículo "¿Qué es un autor?", no es cualquier nombre propio: parece cumplir una función singular. Él se pregunta sobre ella, ¿es el autor el punto de intersección de vida y escritura? ¿Se encuentra en una zona limítrofe entre la "ficción" y la "realidad", o desaparece en el lenguaje?

En su particular lectura del Ecce Homo nietzscheano, Jacques Derrida va incluso más lejos: aunque en la historia de la metafísica los nombres propios, las firmas, la biografía y la autobiografía no han sido más que asuntos secundarios, se pregunta si no será todo aquello el propio lugar en disputa, el asunto mismo del pensamiento de Nietzsche, como también plantea si no será la relación entre el cuerpo biográfico y el cuerpo textual el punto de partida para toda reflexión filosófica (1984a).

Pero para entender las discusiones en torno a este tipo particular de nombre, hay que echar al menos un vistazo a la historia de la figura autorial, institución que no siempre existió como hoy la conocemos. Desde su nacimiento jurídico en el siglo XVIII, han sido los aportes sucesivos del Romanticismo (y su teoría del "genio") y el positivismo (nacimiento de la filología y de la crítica historicista y biográfica), los que han ido definiendo su silueta. El autor es una figura principal de la modernidad, que ha sido objeto de reflexiones y cuestionamientos principalmente a partir del estructuralismo. Pero son sobre todo las corrientes postestructuralistas (particularmente el deconstruccionismo derrideano y el esquizoanálisis de Gilles Deleuze) las que permiten visualizar la figura del autor como el punto de contacto privilegiado entre las prácticas discursivas que llamamos filosofía y literatura, como también entre la ficción y la verdad. De este modo, el autor constituye "la bisagra que hace posible el pliegue, el desdoblamiento y la cópula" entre una y otra: "Ese borde inextenso, ese gozne invisible que las anuda y desanuda sin cesar no es otro que el autor, el nombre propio del autor y el concepto mismo de autor", plantea Antonio Campillo (26), en la línea abierta por Foucault.

¿Qué es un autor? Un diccionario lo define del siguiente modo:

AUTOR. [...]. Dos acepciones tiene esta palabra en sentido jurídico: $1^{a}$. El principal de los delincuentes, ó sea, el que ya directamente por sí mismo, ya induciendo á otra persona, ya cooperando de un modo necesario, ha cometido un acto criminal punible, de cuva acepción se tratará en la palabra DELINCUENTE; $2^{a}$. El que concibe y realiza alguna obra cientifica, 
autor) que de esta propiedad se derivan, de todo lo cual se tratará en PROPIEDAD...

(Enciclopedia Universal Ilustrada Europeo-Americana Espasa-Calpe, 1184).

Curiosamente, propiedad y delincuencia aparecen juntas en esta definición; la literatura, no obstante, es un espacio de apropiaciones y transgresiones (o rupturas) y estas últimas surgen muy particularmente en ese momento de desvinculación que significa el estatuto "legal" del autor: el autor se convierte en "propietario" de un objeto, que es el libro. Como contrapartida, hace su aparición el autor "criminal”, el destructor del libro, o el constructor de un solo libro, un libro que abarque todas las posibilidades de la escritura (el famoso caso de Stéphane Mallarmé). Dicha aparición se produce hacia 1850, con el desarrollo de la poesía simbolista en Francia. ${ }^{3}$

En sus orígenes, la figura autorial es trazada, principalmente, a partir de la legalidad: historia del autor, historia de sus derechos, de sus avances en el campo social y cultural. Antes de esa historia, existe cuanto puede referir la antropología, conocimiento que estructuralistas como Barthes, en su pasión por el problema del lenguaje, emplean para delinear una suerte de punto cero en la evolución de los pueblos, previo a la invención de la escritura, en que no existía ni siquiera remotamente un "autor". Plantea Barthes que en el estudio de las sociedades tribales -sociedades a las que la mera presencia del antropólogo contamina de escritura, sustrayéndolos de ese origen impensable para el hombre postmoderno-, se ha descubierto que "el relato jamás ha estado a cargo de una persona, sino de un mediador, chamán o recitador, del que se puede, en rigor, admirar la 'performance' (es decir, el dominio del código narrativo), pero nunca el 'genio'” (Barthes, 1987: 66). En ese mundo oral, "el jefe -como relata esta vez Maurice Blanchot- ha de probar su dominio sobre las palabras: nada de silencio", generando un discurso hueco, insignificante, discurso que se deberá a su propia gente, verdadera emanación de todo poder, verdaderos impulsores de la palabra incesante (Blanchot, 15-16).

Ahora bien, incluso en el mundo de la escritura no se puede hablar, desde un principio, del autor. Existen tradiciones literarias y filosóficas, pero la figura autorial surge recién en virtud del contrato que garantiza la propiedad respecto de la obra: de el/lo original de la obra. Tales garantías pudieron hacerse efectivas recién a comienzos del siglo XVIII: el autor, obra. Tales garantías pudieron hacerse efectivas recién a comienzos del siglo XVIII: el autor,
como afirma Barthes, es una figura moderna, que tiene sus orígenes en una filosofía y una

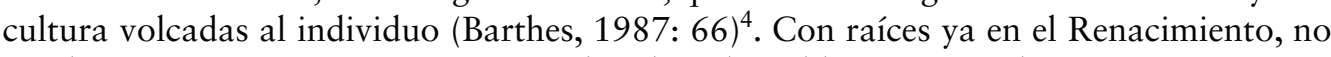
puede sino ejercer un importante papel en la vida pública a partir de su aparición como figura de derecho ${ }^{5}$, habida cuenta de la lucha de los escritores por hacer valer sus intereses ante los libreros editores, lucha que testimonia, entre otros ejemplos, la autobiografía de Goethe (Poesía y verdad).

Esta fecha coincide con el momento en que, según Roland Barthes, la conciencia del escritor se transformó en una conciencia desgarrada e infeliz: "Partiendo de una nada donde el pensamiento parecía erguirse felizmente sobre el decorado de las palabras, la escritura atravesó así todos los estados de una progresiva solidificación: primero objeto de una mirada, luego de un hacer y finalmente de una destrucción, alcanza hoy su último avatar, la ausencia: en las escrituras neutras, llamadas aquí 'el grado cero de la escritura' " (Barthes, 1973 15). É piensa, particularmente, en el desarrollo de la literatura francesa.

"El autor es un personaje moderno, producido indudablemente por nuestra sociedad, en la medida en que ésta, descubre el prestigio del individuo o, dicho de manera más noble, de la 'persona humana'” (Barthes 1987: 66). Roland Barthes plantea en "Pierre Loti: Aziyadé", en El grado cero de la escritura, que la palabra autor viene del latín "auctor", "garante". Pero sin lugar a dudas, hay otras acepciones: "creador, autor" "fuente históridel latin "auctor", "garante". Pero sin lugar a dudas, hay otras acepciones: "creador, autor", "fuente historiEtimológico de la Lengua Castellana. Madrid: Gredos, 2000, p. 73).
La escritura irrumpe, entonces, como propiedad, hecho inaudito en las épocas de rapsodas y juglares: extirpada del cuerpo social, forma parte del cuerpo privado y su sacralidad ya no se vincula con el aliento divino o la acción de las musas, sino con lo sagrado-jurídico, con lo prohibitivo de la sentencia. Al culto del individuo se suma el de la propiedad y la publicidad de la obra. Surge el autor como propietario y a la vez se impone estudiar la literatura historiando la sucesión de autores y las hazañas inscritas en sus biografías. A fines del siglo XIX emerge la crítica literaria positivista, que manifestó también su fascinación por el autor "pequeño dios" y por el "genio" literario, residuo romántico que hasta hoy repercute en el lenguaje cotidiano. Para el Roland Barthes estructuralista, este positivismo viene a ser la culminación del culto individual, "resumen y resultado de la ideología capitalista" (Barthes: 1987, 66) que privilegia el estudio de la vida por sobre la indagación del hecho literario propiamente tal.

Sin embargo, poco después de nacido el autor "muere" en manos de la crítica francesa y es proclamado el nacimiento del lector ${ }^{6}$. Los estructuralistas decidieron asaltar la fortaleza del autor y señalar enfáticamente al texto y su estructura como puntos de arranque del comentario crítico. A ello se suma el fortalecimiento de las distintas teorías en torno a la recepción que surgen en esos años en Alemania, Estados Unidos e Italia, principalmente. El acento puesto en el lector y en la concreción de la obra en el acto de lectura desestabiliza la institución autorial. Emergen ciertas concepciones, muy novedosas, de la escritura, a través de autores como Jacques Derrida, Roland Barthes, Maurice Blanchot y otros que la interrogan en cuanto diseminación o movimiento productivo y conflictual, movimiento de goce, espacio del desastre, pensamiento del afuera, encaminamiento desde nada a la nada, encuentro con el otro y los otros, desmantelamiento de un significado trascendental. Esto es, como algo que desencaja toda idea estabilizadora de la literatura en tanto espacio cerrado que depende de un referente que le precede y origina:

La escritura es la destrucción de toda voz, de todo origen. La escritura es ese lugar neutro, compuesto, oblicuo, al que van a parar nuestro sujeto, el blanco-negro en donde acaba por perderse toda identidad, comenzando por la propia identidad del cuerpo que escribe. (Barthes, 1987: 65).

Esta noción de escritura no sólo se deriva de un desarrollo de la "ciencia literaria" es la conclusión casi "lógica” de varios movimientos simultáneos, en diversos ámbitos. A contrapelo de la formación de una conciencia individual como personalidad única, se va constituyendo este otro rasgo fundamental de la cultura: "la gradual metamorfosis de un individuo, que posee una identidad personal e inequívoca, en un signo, una cifra, una imagen que ya no se puede identificar claramente como la de 'una persona concreta'” (Sprinker, 118).

Prácticamente en el mismo momento en que Barthes y otros críticos se refieren a la escritura y el lugar vacío del Autor (fines de los años '60), en el campo de la lingüística Benveniste no hace otra cosa que subrayar que "yo" no es más que el que dice "yo", en un aquí y un ahora: un sujeto y no una persona, una vacancia a ser llenada en cada instante por un nuevo sujeto hablante, una función. El "yo" se convierte en algo inabarcable y secreto; Lacan plantea que es producto de la intersubjetividad, estableciéndose a través del diálogo con el Otro. El "yo" comienza a parecerse, entonces, al texto bakhtiniano: es el producto de unas relaciones dialógicas, de un carnaval de voces que crean y rompen

"El nacimiento del lector se paga con la muerte del Autor" (Barthes, 1987: 71). 
con sus modulaciones, a cada instante, la leve configuración del sujeto y su identidad. E propio texto se convierte en el lugar donde se constituye el sujeto: el psicoanálisis persigue un relato, pero no es el relato de una verdad, es la construcción de un recuerdo, es una versión del pasado que busca alivio (la cura). "El lenguaje no es el predicado de un sujeto, inexpresable, o que aquél serviría para expresar: es el sujeto", escribe Barthes (1981: 73). En su artículo "Escribir, ¿un verbo intransitivo?”, aborda particularmente el problema:

...Escribir, hoy en día, es constituirse en centro del proceso de la palabra, es efectuar la escritura afectándose a sí mismo, es hacer coincidir acción y afección, es dejar al que escribe dentro de la escritura, no a título de sujeto psicológico [...] sino a título de agente de la acción. (1987: 31 )

\section{NOMBRE DE AUTOR}

Sin dentro ni fuera de texto, sin las dicotomías que han caracterizado hasta hoy buena parte de la historia del pensamiento, el autor pareciera ser una institución literaria dudosa que, en su calidad de falsa respuesta o falso oráculo, de principio unificador, constituye sobre todo una especie de dispositivo ideológico al que ya no vale la pena ni negar ni afirmar: ha sido llevado por el remolino de las disoluciones que entraña la propia disolución del sujeto y su unidad.

Quizás una consecuencia de este proceso en la literatura, es que hoy pueda decirse que "la escritura revela un poder secreto, el de ir cayendo en un azaroso anonimato a medida que se escribe" (Pardo, 50). Esto ya se intuye en el proyecto de Mallarmé, tan cercano al del Conde de Lautréamont en este comentario de Maurice Blanchot: "El libro no tiene autor, porque se escribe a partir de la desaparición hablante del autor. Necesita del escritor, en tanto que éste es ausencia y lugar de la ausencia. El libro es libro cuando no remite a alguien que lo haya hecho, tan puro de su nombre y libre de su existencia como lo es del sentido propio de quien lo lee..." (Blanchot, 234). O en este otro párrafo del mismo crítico francés, a propósito de Proust: "Decimos Proust, pero sentimos perfectamente que es otro francés, a proposito de Proust: "Decimos Proust, pero sentimos perfectamente que es otro
muy distinto quien escribe, no solamente algún otro, sino la exigencia misma de escribir una exigencia que utiliza el nombre de Proust, pero no expresa a Proust, que lo expresa sólo desapropiándolo, convirtiéndolo en Otro" (Ibíd.). Se desconfía del autor, o más bien, se piensa en esa ausencia sin nombre y en el impulso de la escritura como condición de la misma. Lo importante, aparentemente, sería lo que se crea en el devenir de las palabras, la creación y la destrucción que impulsa una escritura.

Sin embargo, no se puede abandonar al autor fácilmente: el concepto se encuentra firmemente establecido en los espacios mediáticos y cotidianos. No en vano, a fines de los años '60 -esos años de pasión iconoclasta-, Michel Foucault afirma que "incluso hoy", cuando reconstruimos la historia de un concepto, de un género literario o una escuela filosófica, estas categorías han de parecer débiles o secundarias "en comparación con la sólida y fundamental unidad que es la del autor y la obra" (Foucault, 1994: 790) ${ }^{7}$. traducciones de la autora].
Esta unidad se resiste al asedio teórico y es uno de los ejes fundamentales de los estudios autobiográficos: ¿dónde, sino en la autobiografía, parece más importante? ¿Dónde ha adquirido mayor centralidad la cuestión del autor y su aventura individual? La autobiografía suele poner en relieve precisamente estos contornos. Genera la ilusión de que lo que no debe disolverse jamás es precisamente el "yo" de la persona que publica, la ilusión de que nunca debiera diluirse el nombre -única certidumbre, índice de lo real- que en vano el anonimato, la seudonimia o la heteronimia han rasgado.

Pero, ¿por qué esta insistencia en el autor? ¿Por qué sigue siendo implicado en la lectura, y muy principalmente en la de la autobiografía? Aquí el circulante más valioso parece ser, precisamente, ese nombre que rubrica y enmarca el relato. Y es quizás por el deseo del lector -deseo de poseer un nombre, deseo de nombrar, de decir el nombre del autor, de paladearlo y juzgarlo-, que es necesario.

Poseer el nombre del autor pareciera conferir cierto poder al lector: un poder absoluto que remite a los valores de la verdad y la autenticidad. Al manejar el nombre del autor con todo lo que él parece implicar, el lector está en condiciones de dictar un veredicto sobre el nombre y lo que nombra, sobre la vida expuesta en el papel, sobre los referentes, sobre lo denotado y lo connotado por él. Porque "nombrar es esta violencia que aparta lo que está nombrando para tenerlo bajo la forma cómoda de un nombre...”. (Blanchot, 1959: 40). El nombre del autor es más nombre que nada: es un renombre (ibíd.: 275).

¿Pero es eso el autor: un nombre necesario al que el crítico y los lectores acuden para hacer valer un privilegio, para afirmar algo, para regocijarse en la certidumbre de una presencia desgarrada -el nombre poseído, violentamente separado de lo que nombra- que da sentido al relato de la vida? ¿Un nombre que prodigiosamente vincula al lector con una "realidad extratextual" sobre la cual quizás aquél necesita dictar su veredicto?

Foucault fue uno de los primeros en afirmar que "el ser del lenguaje no aparece por sî mismo más que en la desaparición del sujeto" (Foucault, 1993: 16). En este apartado nos serviremos principalmente de su artículo "¿Qué es un autor?" -aunque toca temas similares en Las palabras y las cosas, El pensamiento del afuera y otros textos- para observar cuáles son los mecanismos que llevan a los lectores a preservar la figura autorial y la ilusión referencial de un sujeto unívoco detrás de la escritura.

Como varios de sus contemporáneos, Foucault niega al autor como sujeto psicológico, como persona que "autoriza" un discurso; la invención de una figura tal, subraya, es de data reciente, y en modo alguno es una "persona real". Aun así, para Foucault todavía merece la pena detenerse en el autor y considerarlo en tanto "función": la función de autor ("fonction <auteur>"; "author-function"). Es evidente que a él le interesa abordar el problema desde lo que ha sido su crítica de los mecanismos de poder y su injerencia en la producción del discurso. Por ello sitúa al autor -"al menos en apariencia"-, "fuera" del texto, antecediéndolo y organizando los modos de ser del mismo.

Foucault opone este al menos en apariencia a lo que estima la indiferencia como principio ético de la teoría de la escritura [écriture], en contraposición a una postura (la suya) más "comprometida" en la crítica del poder: por una cuestión política, no puede resultar indiferente quién esté hablando. En la indiferencia, Foucault ve una especie de regla inmanente, que marca a la escritura no como resultado, sino como predominio de una práctica. Se trata, a su modo de ver, de una práctica referida sólo a sí misma, que acaba por crear un espacio en el cual el sujeto de la escritura desaparece constantemente y le parece urgente ir más allá de la decretada desaparición. Para él, la escritura se instala en un mundo donde el relato ya no es ilustrado por la figura de Scherezade -quien salva su vida a través de 
su fascinante narración ${ }^{8}$-, sino muy por el contrario, representa sobre todo una especie de sacrificio de la vida y de lo vivo. Reflexiona sobre la relación entre escritura y muerte, manifiesta en la borradura de las características individuales del sujeto textual; en esta relación entre el sujeto y el relato "la marca del escritor no es más que la singularidad de su ausencia: él debe asumir el papel del muerto en el juego de la escritura" (Foucault, 1994 $793)^{9}$. No obstante, Foucault pretende ir más allá de este predicamento, para descubrir sus consecuencias e inconvenientes.

En primer lugar, descubre que no se puede desechar al menos la función de autor, porque al considerar "la obra" en su estructura, sus relaciones, su sistema trópico, en fin, desde sí misma y prescindiendo de la poderosa figura autorial, no se suele anteponer el problema de qué es, en efecto, una obra. Foucault argumenta que la función de autor permite organizar los materiales que la conforman. Bajo un denominador común, que es el nombre del autor -cuyas funciones y propiedades, como ya anticipábamos van más allá de las de cualquier nombre propio-, es posible agrupar lo que denomina "obra". Por otra parte, se detiene en el sentido de la noción de escritura, y se pregunta si ella "no traspone las características empíricas del autor en un anonimato trascendental" (Foucault, 1994: 795) ${ }^{10}$. La tachadura de la empiricidad del autor, de su envío al referente, pudiera ser un modo de resignificar en términos trascendentales la afirmación del carácter sagrado de la escritura. Lejos de aceptar un reenvío a concepciones trascendentes y herméticas del arte -cabría discutir esta percepción de la teoría de la escritura como productividad-, el filósofo francés opina que la ausencia del autor debe orientar una investigación sobre las brechas que ha dejado abiertas. En esta tarea, hace uso del análisis efectuado por J. R. Searle sobre los actos de habla, llevándolo al problema del nombre propio y particularmente del nombre de autor, como un caso especial del primero. Foucault enfatiza que todo nombre propio es, más que una pura y simple referencia, también una descripción; tanto el nombre propio como el nombre del autor se sitúan entre los polos de la descripción y la designación: deben tener un cierto vínculo con lo que nombran, si bien en el caso de este último, ese vínculo es tanto más estrecho:

Si percibo, por ejemplo, que Pierre Dupont no tiene los ojos azules o no nació en París, o no es un médico, no quiere decir que este nombre, Pierre Dupont, dejará de referir siempre a la misma persona; por lo tanto el vínculo de designación no será modificado. Por el contrario, los problemas planteados por el nombre de autor son mucho más complejos. Si descubro que Shakespeare no nació en la casa que hoy visitamos, he aquí una modificación que, evidentemente, no alterará el funcionamiento del nombre de autor. Pero si se demostrara que Shakespeare ha escrito el Organon de Bacon, simplemente porque es el mismo autor quien escribió las obras de Bacon y las de Shakespeare, he aquí un tercer tipo de cambio que modifica completamente el funcionamiento del nombre de autor. El nombre de autor no es, pues, exactamente, sólo un nombre propio como los otros. (Foucault, 1994: 797)."

Quizás Foucault alude a este ejemplo teniendo como referencia Todorov en Poétique de la prose, que plantea una relación similar entre narrar y vivi

. le jeu de l'écriture".

"... ne transpose pas, dans un anonymat transcendantal, les caractères empiriques de l'auteur".

1 “'Si je m’aperçois, par exemple, que Pierre Dupont n’a pas les yeux bleus, ou n’est pas né à Paris, ou n'es pas médecin, etc., il n'en reste pas moins que ce nom, Pierre Dupont, continuera toujours à se référer à la même personne; le lien de désignation ne sera pas modifié pour autant. En revanche, les problèmes posés par le nom d'auteur sont beaucoup plus complexes: si je découvre que Shakespeare n'est pas né dans la maison
Estas diferencias pueden resultar del hecho de que un nombre de autor no es solamente un elemento en el discurso (capaz de ser tanto sujeto como objeto, o ser reemplazado por un pronombre), sino que juega un determinado papel con atención al discurso narrativo, asegurando una función clasificatoria. Ordena un grupo de textos bajo un mismo nombre, indicando de esta forma un cierto modo de ser del discurso. El nombre, dice Foucault, estaría siempre delimitando los "bordes" del texto. Funciona como una suerte de "marco" que delimita los discursos y determina no sólo un modo de ser del discurso, sino, sobre todo, sus modos de lectura. La misma idea de corpus, casi ineludible al momento de especificar los "límites" de una investigación o una interpretación textual, es posible gracias a la función de autor.

Los discursos, como recalca Foucault, son siempre objetos de apropiación; ésta se origina en los mecanismos de propiedad penal/legal que acompañan al surgimiento del autor en el siglo XVIII. En la medida que se erige como producto y que el castigo legal del autor se hace posible, el discurso, antes "...un acto que estaba situado en el campo bipolar de lo sagrado y lo profano, de lo lícito y lo ilícito, de lo religioso y lo blasfemo" (Foucault, 1994: 799 $)^{12}$, llega a convertirse en mercancía. Sin embargo, aun así el discurso ha podido recuperar cierto poder de transgresión. Con el tiempo, ha llegado a redescubrirse el campo bipolar del discurso, restaurándose el peligro a una escritura garantizada por la propiedad, delimitada en este sentido no sólo en el ámbito de la enunciación del discurso, sino también en cada momento de su circulación: de ahí, por ejemplo, la posmoderna circulación de la cita, como una forma de apropiación a través de la lectura-escritura.

La función de autor, además de descriptiva y clasificatoria, no se desarrolla espontáneamente como la atribución de un discurso a un individuo, sino que resulta de una compleja operación en que se construye al ser racional denominado autor. En este punto, Foucault parece coincidir con la teoría de la recepción: lo que la crítica intenta establecer como motivaciones del autor, lo que intenta adivinar en la obra, no es más que “...la proyección [...] del tratamiento que aplicamos a los textos, los acercamientos que realizamos, los rasgos que establecemos como pertinentes, las continuidades que admitimos o las exclusiones que practicamos" (Foucault, 1994: 801) ${ }^{13}$, aun cuando advierte que existen ciertas constantes históricas en la construcción autorial. Seguidamente, se refiere a las vías de autentificación de la obra de un autor y al autor como principio unificador de la escritura; en este sentido, su papel es el de neutralizar las contradicciones entre los textos, es más, ser un punto de resolución de las contradicciones en una suerte de continuidad histórica, biográfica y psicológica que tiene como eje la figura autorial.

La función de autor se presenta, pues, como una especie de normativización de la lectura que busca la congruencia textual y no su desgarro, su fisura. En un mismo sentido, cuando Philippe Sollers describe las lecturas "esencialistas", alude al carácter homogeneizador de la lectura hecha con la mirada puesta en el autor. Para Foucault, la función del autor qu'on visite aujourd'hui, voilà une modification qui, évidemment, ne vas pas altérer la fonctionnement du que c'est le même auteur qui a écrit les oeuvres de Bacon et celles de Shakespeare, voilà un troisième type de changement qui modifie entièrement le fonctionnement du nom d'auteur. Le nom d'auteur n'est don pas exactement un nom propre comme les autres".

“...un acte qui était placé dans le champ bipolaire du sacré et du profane, du licite et de l'illicite, du religieux et du blasphématoire"

La projection [...] du traitement qu' on fait subir aux textes, des rapprochements qu' on opère, des traits qu'on établit comme pertinents, des continuités qu'on admet, ou des exclusions qu'on practique”. 
constituye una especie de entelequia: el autor es un lugar que le compete al sujeto como variable y compleja función del discurso mismo. Hasta hoy ha sido incuestionable su "verdad", su "presencia"; ésta se ha hecho necesaria ya que logra repeler "el gran riesgo, el gran peligro con que la ficción amenaza nuestro mundo...” (Foucault, 1994: 809)14. La respuesta ideológica a esta ansiedad, postula Foucault, es ni más ni menos que el autor. Gracias a él es posible limitar "la cancerosa, peligrosa proliferación de significaciones en un mundo donde se es económico no sólo de sus recursos y riquezas, sino también de sus propios discursos y de sus significaciones" (ibíd.) ${ }^{15}$.

Finalmente, lo que le interesa a Foucault es que la idea tradicional de "autor" -aquella que ha primado durante casi tres siglos en la lectura crítica- es en realidad "ideología”, en el sentido de falacia o mentira:

Tenemos la costumbre de decir [...] que el autor es la instancia creadora que brota de una obra donde él deposita, con una infinita riqueza y generosidad, un mundo inagotable de obra donde él deposita, con una infinita riqueza y generosidad, un mundo inagotable de significaciones [...] La verdad es otra: el autor no es una fuente indefinida de significaciones que vendría a llenar la obra; el autor no precede a las obras. Es un cierto principio funcional a través del cual se traba la libre circulación, la libre manipulación, la libre composición, descomposición, recomposición de la ficción. (Ibíd..). ${ }^{16}$

En suma, el texto de Foucault no sólo critica el encubrimiento que conlleva la creación de la figura autorial (figura que es en realidad un ente de razón): antes de declarar la muerte del autor, pasa por una apropiación de su figura, con el fin de poder emprender un análisis y una historia del discurso, en el sentido genealógico propio de los trabajos de este pensador

Es indudable que alienta en los lectores un insaciable "deseo de autor", aunque en el artículo de Foucault sea éste apenas un verdadero deseo, y el anhelo de la figura autorial se presente, sobre todo, como una necesidad. Por el contrario, para Roland Barthes -el otro pilar de esta reflexión- el deseo de autor sigue movilizando la lectura. Situado en un "grado cero" del que se puede esperar todo y nada, el autor:

..Como institución está muerto; su persona civil, pasional, biográfica, ha desaparecido; desposeída, ya no ejerce su obra la formidable paternidad cuyo relato se encargaban de establecer y renovar tanto la historia literaria como la enseñanza y la opinión. Pero en el texto, de una cierta manera, yo deseo al autor: tengo necesidad de su figura (que no es ni su representación ni su proyección), tanto como él tiene necesidad de la mía (salvo si sólo 'murmura')... (Barthes, 1989: 46).

En los textos de Barthes, la complicidad del deseo hace posible la escritura y la lectura de goce. Habida cuenta de las necesidades y deseos aún vigentes, pareciera ser que la pregunta de Samuel Beckett (“¿qué importa quién está hablando?”, cit. por Foucault, 1994: 789), aunque justa, quizás deba ser postergada. El luto por el autor puede esperar.

" $\ldots$ le grand péril, le grand danger par lesquels la fiction menace notre monde".

"La prolifération cancérisante, dangereuse des significations dans un monde où l'on est économe non seulement de ses resources et richesses, mais de ses propres discours et de leurs significations", (Foucault, ibíd.).

"Nous avons coutume de dire [...] que l'auteur est l'instance créatrice jaillissante d'une oeuvre où il dépose, avec une infinie richesse et generosité, un monde inépuisable de significations [...] La vérité est tout autre: l'auteur n'est pas une source indéfinie de significations qui viendraient combler l'oeuvre, l'auteur ne précède pas les oeuvres. Il est un certain principe fonctionnel par lequel on entrave la libre circulation, la libre manipulation, la libre composition, décomposition, recomposition de la fiction..."

\section{EL NOMBRE DE AUTOR COMO LUGAR DE DUELO: AUTOBIOGRAFÍA Y AUTOTA-}

\section{NATOGRAFÍA}

Finalmente, deseo plantear el problema del nombre de autor inscrito en la autobiografía. Isidore Ducasse intentó borrar toda traza biográfica para alumbrar, él mismo, a través de su escritura, al "Conde de Lautréamont", gesto que, recuerda Philippe Sollers, se repite en la declaración de otro poeta maldito, Antonin Artaud: "yo, Antonin Artaud, soy mi hijo/ mi padre, mi madre/ y yo" (cit. por Sollers, 1978: 148) ${ }^{17}$. Sin embargo, otros autores afirman obsesivamente sus nombres -heredados-, inscribiéndolos en la centralidad del relato autobiográfico o, como Borges, en cada rincón de su obra. Independientemente del nombre de autor como práctica social, como función que organiza unos discursos, ¿cuál es el poder de este nombre, por qué autogestionarlo, por qué inscribirlo? ¿Qué lugar ocupa el nombre de autor en la escritura autobiográfica?

El pensamiento del teórico de la autobiografía Philippe Lejeune pivota en gran medida sobre el tema del nombre propio. En un famoso artículo, "El pacto autobiográfico" (1975), este autor define la autobiografía como "relato retrospectivo en prosa que una persona real hace de su propia existencia, poniendo énfasis en su vida individual y, en particular, en la historia de su personalidad" (Lejeune, 50). Subrayo persona real porque tan sólo unos años antes, en una primera definición, Lejeune planteaba como sujeto de su enunciado simplemente a "alguien". El reemplazo tiene mucho sentido. Con vistas al problema de la referencialidad del texto autobiográfico (que Lejeune afirmaba con vehemencia en los 70), había que precisar ese "alguien" y decir que la autobiografía es la escritura de una persona concreta, que la escritura de la vida y la vida misma guardan una relación estrecha, aunque limitada por las posibilidades del recuerdo y la expresión (el lenguaje).

El signo que indica la presencia de esa persona real es, para Philippe Lejeune, el nombre: de este modo, descubre el papel del nombre propio como "tema profundo de la autobiografía" (Lejeune, 73). A su modo de ver, se puede diferenciar entre autobiografía y ficción a partir de la identidad del nombre propio compartido por el autor, el narrador y el protagonista. Lo que llama "pacto autobiográfico" es la afirmación de esa identidad en el texto, mediada por la lectura. De esta forma, y con el fin de establecer el "género autobiográfico", abandona la perspectiva centrada en el autor y sus intenciones (que deben ser documentadas y que constituyen una evidencia no implícita en el texto), por la perspectiva del lector, quien, a través de ese signo -el nombre- puede establecer si está leyendo o no una autobiografía.

Lo que Lejeune intentaba afirmar (contra viento y marea en aquellos años) es que el nombre propio atrae una presencia al texto, sin la cual ya no es posible discernir entre lo real y lo ficcional. Justificaba su opción sirviéndose de la lingüística, particularmente del enfoque del lingüista estructuralista Émile Benveniste:

Benveniste indica que no hay concepto del "yo": aseveración muy acertada si añadimos que no hay concepto de "él”, y que, en general, ningún pronombre personal, posesivo, demostrativo, etc., ha remitido jamás a un concepto, sino que ejerce simplemente una función, que consiste en enviar a un nombre o a una entidad susceptible de ser designada por un nombre. (Lejeune, 59).1

Sollers, Philippe. La escritura y la experiencia de los limites, op. cit., p. 148. Sollers se refiere detenidamente a ambos creadores.

En lo relativo a los pronombres personales, cfr. los capítulos XIII y XIV ("Estructura de las relaciones de 
Este envío, en lo que refiere a la primera persona, al yo, remite al nombre propio, en el cual, enfatiza Lejeune, persona y discurso se articulan "antes mismo de articularse en la primera persona, como lo muestra el orden de la adquisición del lenguaje por los niños" (ibíd.), y añade: "la adquisición del nombre propio es, sin duda alguna, una etapa tan importante en la historia del individuo como la del estadio del espejo" (Lejeune, 74).

En un artículo posterior de Lejeune, "La autobiografía en tercera persona", es posible hallar la siguiente afirmación: "cualquier análisis un poco profundo del juego de los pronombres y de las personas en la enunciación nos lleva obligatoriamente a construir una teoría del sujeto. 'La identidad' es una relación constante entre la unidad y lo múltiple” (Lejeune, 93). El nombre sería, desde esta perspectiva léxica, un garante de la unidad del sujeto, un elemento de estabilidad en el tiempo, aquello que pese al paso de los años permite decir “y sigo siendo Fulano"... Obviamente, tal estabilidad en un plano léxico puede ser sólo una ilusión más del lenguaje... Desde una perspectiva ética y filosófica, por cierto, habría mucho que objetar a esta postura sobre la subjetividad y la identidad. Lejeune, sin embargo, no pretende iniciar esa discusión: lo que le interesa es diseñar un modelo heurístico que resuelva los problemas planteados por la autobiografía en tanto género referencial, desde una pragmática de la comunicación literaria.

Mientras en el discurso oral se vuelve al nombre propio cuando es necesario (por ejemplo, si alguien desea presentarse), en el discurso escrito la firma es la que designa al enunciador. Para Lejeune, el nombre de la portada -para él, la firma- de un libro resume "toda la existencia de lo que llamamos el autor" (Lejeune, 60), su realidad extratextual indudable y su responsabilidad como enunciador del texto. Desde esta perspectiva, un autor-esa presencialausencia conflictiva- "es una persona que escribe y publica. A caballo entre lo extratextual y el texto, el autor es la línea de contacto entre ambos” (Lejeune, 61).

En virtud de la presencia del autor, señalada por el nombre/firma, es posible determinar, según Lejeune, si se está más o no ante una autobiografía. Su propuesta encontrará fuertes detractores, particularmente en lo referente al nombre propio, la firma y el carácter referencial del género, entre autores como Paul de Man y Jacques Derrida.

En el libro de entrevistas Posiciones Jacques Derrida afirma que "todo discurso -literario o no- es una extensión del nombre propio" (cit. por Catelli, 1991: 62), frase que niega la especificidad autobiográfica buscada por Lejeune. Paul de Man, por otra parte, procura dinamitar la distinción entre ficción y realidad, ineludible en el pensamiento d Lejeune. Se opone a lo que entiende como una perspectiva trascendental e idealista de la autobiografía, perspectiva que supone una lógica de la reflexividad y de la autopresencia como fundamento de todo discurso autobiográfico: la representabilidad de la vida a través del lenguaje, la correspondencia entre vida y escritura. Si el lenguaje representa, es porque tiene cierta fuerza figural; pero para De Man la figuralidad elemental de la vida, de la vida como prosopopeya, hace que la distinción entre autobiografía y ficción sea indecidible (Moreiras, 129).

Según Alberto Moreiras (autor que estudia lo que llama autografía en los textos de Jacques Derrida y Friedrich Nietzsche) es importante señalar que Paul de Man ve en el discurso de la autobiografía un discurso de autorrestauración, que sin embargo se ve limitado por una instancia extralingüística, por un "apuro lingüístico" que llamamos muerte y que Moreira denomina, me parece que siguiendo a Lacan, "la presión de lo real": "A esta presión res- ponde la pulsión de escritura, que hace de la autobiografía no tan sólo autorrestauración, sino sobrevivencia" (ibíd). En este sentido, Moreiras sostiene que existe cierta indecibilidad de la autobiografía, por faltarle su hecho sustancial: la muerte. La prosopopeya de la voz y del nombre, como dice Paul de Man, se juega entonces a pesar de esta falta y por ella misma, falta que Roland Barthes llama, en La cámara lúcida, el punctum, aquel lugar de duelo o herida a la que responde la escritura (Barthes, 1990).

"Para una práctica no-trascendental de la autobiografía -propone Moreiras- el problema no es la indecibilidad entre ficción y verdad, sino la mera decibilidad del nombre propio como nombre único y únicamente heredado" (Moreiras, 130), el nombre como lugar en torno al cual gira la práctica restauradora de la autobiografía que será también una práctica tanatográfica: dado que el discurso girará sobre la vida -entendida como bios, esto es, como decurso temporal, y no como zoé ${ }^{19}-$, deberá estar "entre lo biológico y lo biográfico, lo tanatológico y lo tanatográfico" (Derrida, 1984a : 392 ${ }^{20}$.

La estrategia deconstructivista invita a considerar otro estilo de autobiografía y otra forma de visualizar no sólo lo que Lejeune considera, en un sentido reducido, lo autobiográfico, sino también el propio discurso filosófico en cuanto autografía:

...una nueva problemática de lo biográfico en general, de la biografía de los filósofos en particular, debe movilizar otros recursos, y al menos un nuevo análisis del nombre propio y de la ticular, debe noviliza "iro y de la frma. Ni las lecturas "inmanas ni las lecturas empírico-genéticas externas han interrogado jamás, en cuanto tales, la dynamis de este borde entre la "obra" y la "vida", el sistema y el "sujeto" del sistema. Este borde [... no es activo ni pasivo, no está afuera ni dentro. Sobre todo, no es una línea delgada, un trazo invisible o indivisible entre el cerco de los filosofemas, por una parte y, por otra, la "vida" de un autor ya identificable bajo su nombre. Este borde divisible atraviesa los dos "cuerpos",

el corpus y el cuerpo, según leyes que nosotros sólo comenzamos a entrever. (Derrida, ibíd.).

Para Derrida el problema del nombre es importante; el nombre, que es siempre "y a priori un nombre de muerto", queda comprometido por ejemplo en el Ecce homo nietzscheano en su discurso: el nombre es su crédito, a través de él intenta decir algo, pagar su deuda, conferir inmortalidad a quien habrá de morir -él, no su nombre-; darle un porvenir a la propia política nietzscheana (Derrida 1984b). En otros textos, como por ejemplo en su argumentación contra las tesis de Austin acerca de lo que éste llamó "performative utterances" (expresiones realizativas), Derrida aborda los problemas del contexto, la iterabilidad y la citabilidad de toda marca; finalmente, confronta los postulados de Austin acerca de la firma. Para Austin, existe siempre una fuente de la enunciación, ya sea oralmente como a través de la escritura. Cuando se trata de la escritura, la fuente de un enunciado en primera persona viene avalada por la firma, que implicaría un yo determinado. Derrida analiza esta afirmación: por definición, la firma escrita implica la no-presencia actual o empírica del signatario, al tiempo que habrá estado ahí en un pasado actual o en un futuro: se trata del

1 Palabra griega que significa "vida". Para los griegos, la vida se podía significar de dos modos muy distintos: $z o e ́$, la vida sin caracterización, la vida infinita, y bios, que señala los contornos y rasgos característicos de una vida en particular, la vida con su caracterización y que en modo alguno se opone a la muerte, en cuanto esta Habría que considerar ella misma. De este modo, se podría decir que la muerte forma parte de la biografía. entre bios y zoé, cfr. Kerényil, Karl. (1988). Dionisios. Raiz de la vida indestructible. Barcelona: Herder, principalmente la introducción: "Vida finita y vida infinita en la lengua griega".

20 "... entre le biologique et le biographique, le thanatologique et le thanatographique". 
mantenimiento que está inscrito en la forma misma de la firma: "Ahí está la originalidad enigmática de todas las rúbricas -señala Derrida-. Para que se produzca la ligadura con la fuente, es necesario, pues, que sea retenida la singularidad absoluta de un acontecimiento de firma y de una forma de firma: la reproductibilidad pura de un acontecimiento puro" (Derrida, 1998: 370).

Sin embargo, es cuestionable que exista esa "singularidad absoluta" pues el efecto de firma -que acontece cotidianamente- es posible gracias a la imposibilidad de su pureza rigurosa: "Para funcionar [...] para ser legible, una firma debe poseer una forma repetible, iterable, imitable" (Ibíd., 371); con estas palabras Derrida no sólo sienta ciertas bases para una reflexión sobre la firma (él mismo firma ${ }^{21}$ su comunicación antes de enviarla al congreso donde la presentó), sino que también confronta su concepto de escritura y diseminación al sistema de Austin, haciendo que éste se encuentre ante sus propios límites.

Para Derrida, "la firma inventa a quien firma" (Derrida, 1984a: 22). El asunto deja de ser tan sencillo como lo planteaba Lejeune, cuando manejaba en sus definiciones las palabras "firma" y "nombre", indistintamente. Nietzsche ofrece los ejemplos necesarios para Derrida. Desde su óptica, éste hizo de todo lo que escribió sobre vida y muerte "una inmensa rúbrica autobiográfica" (Derrida, 1984b: 61) si se entiende la rúbrica como fir$m a$, hay que pensar, entonces, que todo lo que Nietzsche escribió fue una gran invención según la etimología, la rúbrica (del lat. rûbrîca, "tierra roja”) es un "título escrito en rojo" (Corominas, 515), pero también por alusión o semejanza se llama así a la sangre que se derrama para testificar una verdad. La palabra rúbrica es rica en sugerencias, sobre todo porque de alguna manera vincula texto y vida, texto y sangre, sangre y verdad. La "inmensa rúbrica" se torna dramática, pero sobre todo poética, con la poesía que puede tener la invención de la firma y de la vida. Las palabras sangran y tiñen con su sangre el discurso autobiográfico, mitográfico, tanatográfico.

Pero todavía Derrida aporta algo más sobre la firma, el nombre y la escritura autobiográfica (o "autográfica"). Para este pensador, esta escritura es una forma de pagar una deuda con la vida: el propio autobiógrafo es el remitente y el destinatario de su escritura. De este modo, señala Alberto Moreiras, la firma "tiende a cubrir la separación entre remitente y destinatario cuando ambos están unidos por la mismidad del nombre propio" (Moreiras: 132), así se convierte más bien en la traza de una diferencia que de una identidad, y "sólo retornará a la identidad en el momento de su recepción por el destinatario" (ibíd.). Por ello, dice, para Derrida la autobiografía no puede ser otra cosa que heterobiografía: "es la oreja del otro la que firma", como escribe Derrida en la presentación de Otobiographies.

La firma se encuentra, entonces, en un borde paradójico: entre sí y sí, entre el yo que se escribe a sí mismo, el que se lee y aquél otro que presta su oído al acto de contar la vida. Del mismo modo, también el nombre propio del autor se encuentra en un borde indecidible, cuando se inscribe como restauración de la vida y a la vez delata con su presencia una incompletitud, una ausencia: la falta, la deuda, la ausencia de muerte.

En un gesto análogo al de Roland Barthes en su Roland Barthes, Derrida acompaña este trazo incierto de un comentario: "Nota. El texto - escrito- de esta comunicación oral debía ser enviado a la Asociación de le sociedades de filosofía de lengua francesa antes de la sesión. Tal envío debía, por tanto, ser firmado. Lo que yo he hecho y remedado aquí. ¿Dónde? Allá. J. D.” (Derrida, 1998: 372). Me parece que así, en su ausencia, queda aún por establecer la estabilidad de la firma, "el remedo" que es publicado y leído como marca de una supuesta presencia del autor

\section{REFERENCIAS}

Austin, John Langshaw. (1990). Cómo hacer cosas con palabras. Barcelona: Paidós Barthes, Roland. (1990). Cámara lúcida. Barcelona: Paidós.

- (1981). Crítica y verdad. México: Siglo XXI.

- (1973). El grado cero de la escritura (seguido de Nuevos ensayos críticos). Buenos Aires: Siglo XXI.

—. (1978). Roland Barthes por Roland Barthes. Barcelona: Kairós.

- (1987). El susurro del lenguaje. Más allá de la palabra y la escritura. Buenos Aires, Paidós. Blanchot, Maurice. (1959). El libro que vendrá. Caracas: Monte Ávila Editores.

—. (1990). La escritura del desastre. Caracas: Monte Ávila.

Borges, Jorge Luis. (1999a). Historia de la eternidad. En Obras completas. Vol. I. Barcelona: Emecé.

-. (1999b). Otras inquisiciones. En Obras completas. Vol. II. Barcelona: Emecé.

Campillo, Antonio. (1992). "El autor, la ficción, la verdad”. Daimon, Revista de Filosofía 5: $25-45$.

Catelli, Nora. (1991). El espacio autobiográfico. Barcelona: Lumen.

Corominas, José. (2000). Breve diccionario etimológico de la lengua castellana. Madrid: Gredos.

De Man, Paul. (1991). "La autobiografía como desfiguración”. En Suplementos Anthropos 29: 113-117.

Derrida, Jacques. (1998). "Firma, acontecimiento, contexto”. Márgenes de la filosofía. Madrid: Cátedra.

-. (1984a). Otobiographies. L'enseignement de Nietzsche et la politique du nom propre. Paris: Galilée.

—. (1984b). "Nietzsche: Políticas del nombre propio". En La filosofía como institución. Barcelona: Juan Granica.

Fokkema, D. W. y E. Ibsch. (1981). Teorías de la literatura del siglo XX. Madrid: Cátedra. Foucault, Michel. (1994). “Qu' est-ce qu' un auteur?”. En Dits et écrits. 1954-1988. Volumen I, 1954-1969. Paris: Gallimard. (Publicada originariamente en Bulletin de la Société Française de Philosophie, año 63, №3, julio-septiembre de 1969, pp. 73-104). Versión inglesa: "What Is an Author?". En: Harari, Josué V. (Ed.) (1979). Textual Strategies. Perspectives in Post-Structuralist Criticism. Ithaca: Cornell University Press: 141-160. Perspectives in Post-Structuralist Criticism. Ithaca: Cornell
-. (1993). El pensamiento del afuera. Valencia: Pre-Textos.

Jay, Paul. (1993). El ser y el texto. (La autobiografía, del Romanticismo a la postmodernidad). Madrid: Megazul-Endymion.

Kerényi, Karl. (1988). Dionisios. Raíz de la vida indestructible. Barcelona: Herder.

Lejeune, Philippe. (1994). El pacto autobiográfico y otros estudios. Madrid: MegazulEndymion.

Molloy, Sylvia. (1979). Las letras de Borges. Buenos Aires: Sudamericana.

Moreiras, Alberto. (1991). "Autografía: pensador firmado. (Nietzsche y Derrida)". En Suplementos Anthropos 29: 129-36.

Pardo, José Luis. (1977). Transversales. Texto sobre los textos. Barcelona: Anagrama.

Platón. (1982). Cratilo o del lenguaje. Traducción, notas e introducción de Vicente Becares Botas. Salamanca: Universidad de Salamanca.

Proust, Marcel. (1970). "Apellidos de personas”. En Ensayos literarios (Contra SainteBeuve), vol. II. Barcelona: EDHASA. 
Sollers, Philippe. (1978). La escritura y la experiencia de los límites. Valencia: Pre-Textos. —. (1971). "Un paso sobre la luna”. En Derrida, Jacques. De la gramatología. Buenos Aires: Siglo XXI.

Sprinker, Michael. (1991). "Ficciones del ‘yo': el final de la autobiografía”. En Suplementos Anthropos 29: 118-128.

Steiner, George. (1980). Después de Babel. Aspectos del lenguaje y la traducción. España: FCE.

Todorov, Tzvetan. (1971). "Les hommes-récits”. En Poétique de la prose. París: Seuil.

VVAA. (1991). Enciclopedia Universal Ilustrada Europeo-Americana. Madrid: Espasa-Calpe.

Recepción: martes 29 de septiembre de 2009 Aceptación: viernes 8 de enero de 2010 